Article

\title{
Fused 1,2,3-Dithiazoles: Convenient Synthesis, Structural Characterization, and Electrochemical Properties
}

\author{
Lidia S. Konstantinova ${ }^{1,2}$, Ilia V. Baranovsky ${ }^{1}$, Irina G. Irtegova ${ }^{3}$, Irina Y. Bagryanskaya ${ }^{3,4}$, \\ Leonid A. Shundrin ${ }^{3,4}$, Andrey V. Zibarev ${ }^{3,5}$ and Oleg A. Rakitin ${ }^{1,2, *}$ \\ 1 N. D. Zelinsky Institute of Organic Chemistry, Russian Academy of Sciences, 119991 Moscow, Russia; \\ konstantinova_ls@mail.ru (L.S.K.); ilay679@rambler.ru (I.V.B.) \\ 2 Nanotechnology Education and Research Center, South Ural State University, 454080 Chelyabinsk, Russia \\ 3 N. N. Vorozhtsov Institute of Organic Chemistry, Siberian Branch, Russian Academy of Sciences, \\ 630090 Novosibirsk, Russia; irteg@nioch.nsc.ru (I.G.I.); bagryan@nioch.nsc.ru (I.Y.B.); \\ shundrin@nioch.nsc.ru (L.A.S.); zibarev@nioch.nsc.ru (A.V.Z.) \\ 4 Department of Natural Sciences, National Research University-Novosibirsk State University, \\ 630090 Novosibirsk, Russia \\ 5 Department of Chemistry, National Research University-Tomsk State University, 634050 Tomsk, Russia \\ * Correspondence: orakitin@ioc.ac.ru; Tel.: +7-499-135-53-27; Fax: +7-499-135-53-28
}

Academic Editors: Panayiotis A. Koutentis and Andreas S. Kalogirou

Received: 28 March 2016; Accepted: 29 April 2016; Published: 6 May 2016

\begin{abstract}
A new general protocol for synthesis of fused 1,2,3-dithiazoles by the reaction of cyclic oximes with $\mathrm{S}_{2} \mathrm{Cl}_{2}$ and pyridine in acetonitrile has been developed. The target 1,2,3-dithiazoles fused with various carbocycles, such as indene, naphthalenone, cyclohexadienone, cyclopentadiene, and benzoannulene, were selectively obtained in low to high yields. In most cases, the hetero ring-closure was accompanied by chlorination of the carbocyclic moieties. With naphthalenone derivatives, a novel dithiazole rearrangement $(\mathbf{1 5} \rightarrow \mathbf{1 3})$ featuring unexpected movement of the dithiazole ring from $\alpha$ - to $\beta$-position, with respect to keto group, was discovered. Molecular structure of 4-chloro-5H-naphtho[1,2-d][1,2,3]dithiazol-5-one 13 was confirmed by single-crystal X-ray diffraction. Electrochemical properties of $\mathbf{1 3}$ were studied by cyclic voltammetry and a complex behavior was observed, most likely including hydrodechlorination at a low potential.
\end{abstract}

Keywords: fused 1,2,3-dithiazoles; synthesis; sulfur monochloride; X-ray diffraction; cyclic voltammetry

\section{Introduction}

1,2,3-Dithiazoles, the five membered sulfur-nitrogen heterocycles, are promising for science and technology because of their biological activity, unusual chemical transformations and interesting physical properties [1-3]. In particular it has been shown that the 1,2,3-dithiazole scaffold can be effectively used in the design and synthesis of stable neutral and negatively charged radicals (i.e., radical anions) - actual or potential building blocks for molecule-based conductive and/or magnetic functional materials [4-7]. One can imagine that continued exploration of the 1,2,3-dithiazole chemistry is guaranteed to yield new compounds of fundamental and/or applied significance.

Normally, monocyclic 1,2,3-dithiazoles are prepared from 4,5-dichloro-1,2,3-dithiazolium chloride (the Appel salt) as the key synthon [8,9]. Benzo-fused 1,2,3-dithiazolium chlorides (the Herz salts) can be easily prepared by the Herz reaction from aromatic amines and sulfur monochloride $\mathrm{S}_{2} \mathrm{Cl}_{2}$. Although this reaction has been known for about one hundred years, it is still used nowadays as well $[10,11]$. 
Other synthetic precursors of fused 1,2,3-dithiazoles are cyclic oximes used in reactions with $\mathrm{S}_{2} \mathrm{Cl}_{2}$ in the presence of organic bases such as $\mathrm{N}$-ethyldiisopropylamine (Hünig's base) and triisobutylamine. The disadvantage of this method is that no general procedure is established and in all cases arduous purification of products by column chromatography is required [12-15].

During our ongoing work with $\mathrm{S}_{2} \mathrm{Cl}_{2}$ we have found that the reaction conditions and nature of the organic base have a crucial role influencing the yields of the target sulfur-nitrogen heterocycles [16-19]. It was shown that many nitrogen organic bases, such as tertiary amines, for example 1,4-diazabicyclooctane (DABCO), interact with $\mathrm{S}_{2} \mathrm{Cl}_{2}$ forming ionic complexes in some cases [17]. However, to the best of our knowledge, possible interaction/complexation between $\mathrm{S}_{2} \mathrm{Cl}_{2}$ and such a strong nitrogen organic base such as pyridine has not been investigated.

In this paper we report a study of a reaction between cyclic oximes and $\mathrm{S}_{2} \mathrm{Cl}_{2} /$ pyridine covering selective synthesis of fused 1,2,3-dithiazoles together with their structural characterization by single-crystal X-ray diffraction (XRD) and investigation of their electrochemical properties by cyclic voltammetry $(\mathrm{CV})$.

\section{Results and Discussion}

\subsection{Syntheses}

In an effort to improve the synthesis of fused 1,2,3-dithiazoles, we re-investigated the reaction of 1-indanone oxime 1 with $\mathrm{S}_{2} \mathrm{Cl}_{2}$. Treatment of 1 with $\mathrm{S}_{2} \mathrm{Cl}_{2}$ in dimethylformamide (DMF), i.e., a solvent which is frequently used in $\mathrm{S}_{2} \mathrm{Cl}_{2}$ reactions [16,19], in the temperature range from -25 to $20^{\circ} \mathrm{C}$ gave 8-chloroindeno[1,2- $d]-1,2,3$-dithiazole 2 in low yields. Note, that in this case the hetero ring-closure was accompanied by chlorination. The type of base used was important for the success of reactions with $\mathrm{S}_{2} \mathrm{Cl}_{2}$ in other solvents, such as chloroform or acetonitrile (MeCN). Reaction of $\mathbf{1}$ with a two-fold excess of $\mathrm{S}_{2} \mathrm{Cl}_{2}$ and DABCO in chloroform at $-5{ }^{\circ} \mathrm{C}$ led to complex mixtures containing 2 in the yield of $35 \%$. The best results were achieved by treating 1 with a three-fold excess of $\mathrm{S}_{2} \mathrm{Cl}_{2}$ or a four-fold excess of pyridine in $\mathrm{MeCN}$ at $5{ }^{\circ} \mathrm{C}$ for $1 \mathrm{~h}$ which gave target 2 selectively in $81 \%$ yield (Scheme 1 ). The main feature of this and other $\mathrm{S}_{2} \mathrm{Cl}_{2}$ /pyridine reactions is that the reaction mixtures are not tarry, and the product isolations do not require chromatography in contrast with the literature procedures [12-15].

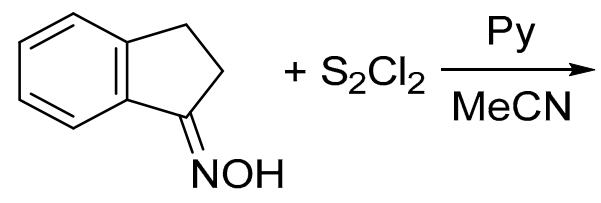

1<smiles>Clc1c2ssnc-2c2ccccc12</smiles>

2, $81 \%$

Scheme 1. Reaction of oxime 1 with $\mathrm{S}_{2} \mathrm{Cl}_{2}$ / pyridine to give dithiazole 2 .

Under the same conditions, 3-phenylindanone oxime 3 gave the corresponding 1,2,3-dithiazole 4 even in a higher yield, meanwhile chlorination was not observed (Scheme 2).<smiles>CC(C)(C)C(=O)C1CC(c2ccccc2)c2ccccc21</smiles>

3<smiles>c1ccc(-c2c3ssnc-3c3ccccc23)cc1</smiles>

4, $90 \%$

Scheme 2. Reaction of oxime 3 with $\mathrm{S}_{2} \mathrm{Cl}_{2}$ / pyridine to give dithiazole 4 . 
Treatment of the archetypal cyclopentanone oxime 5a with an excess of $\mathrm{S}_{2} \mathrm{Cl}_{2}$ (6 equiv) and pyridine (8 equiv) in boiling MeCN gave 4,5,6-trichlorocyclopenta-1,2,3-dithiazole 6a in moderate yield. Using lesser amounts of $\mathrm{S}_{2} \mathrm{Cl}_{2}$ or/and pyridine in an attempt to obtain less chlorinated product failed since only $\mathbf{6 a}$ was isolated in lower yields. With a similar procedure, 4-carbethoxy substituted derivative $\mathbf{5} \mathbf{b}$ was converted into dichlorocyclopentadithiazole $\mathbf{6} \mathbf{b}$ in a good yield (Scheme 3 ). In both cases, the yields of dithiazoles 6 were slightly higher than those reported in the literature $[12,15]$.<smiles>[R]C1CCCC1=NO</smiles>

$$
\begin{aligned}
\text { 5, a R } & =\mathrm{H} \\
\text { b } \mathrm{R} & =\mathrm{CO}_{2} \mathrm{Et}
\end{aligned}
$$<smiles>CNCC(C)(C)Br</smiles><smiles></smiles>
6, a $\mathrm{R}=\mathrm{Cl}, 38 \%$
b $\mathrm{R}=\mathrm{CO}_{2} \mathrm{Et}, 67 \%$

Scheme 3. Reaction of oximes 5 with $\mathrm{S}_{2} \mathrm{Cl}_{2}$ / pyridine to give dithiazoles 6 .

In the previous study on six-membered oximes, $p$-benzoquinone monooxime 7 gave a complex mixture of products on reaction with $\mathrm{S}_{2} \mathrm{Cl}_{2}$ and the desired fused dithiazole was obtained in a low yield [13]. We have found that the treatment of 7 with $\mathrm{S}_{2} \mathrm{Cl}_{2}$ /pyridine in $\mathrm{MeCN}$ leads selectively to dichloro dithiazole 8 or to trichloro dithiazole 9 depending on the molar excess of the reagents. In boiling MeCN, reaction with a larger excess $\left(\mathrm{S}_{2} \mathrm{Cl}_{2}, 6\right.$ equiv; pyridine, 8 equiv) gave 9 , whereas with a smaller excess $\left(\mathrm{S}_{2} \mathrm{Cl}_{2}, 3\right.$ equiv; pyridine, 4 equiv) 8 , in both cases, however, in low yields (Scheme 4 ).<smiles>O=c1c(Cl)cc2nssc-2c1O[AsH2]</smiles>

$8,15 \%$<smiles>O=C1C=CC(=NO)C=C1</smiles>

7

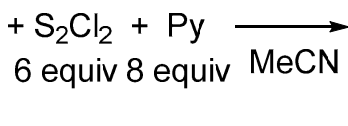<smiles>O=c1c(Cl)c2ssnc-2c(Cl)c1Cl</smiles>

9, $13 \%$

Scheme 4. Reaction of oxime 7 with $\mathrm{S}_{2} \mathrm{Cl}_{2}$ /pyridine to give dithiazoles 8 and 9 .

Treatment of benzosuberone oxime $\mathbf{1 0}$ with $\mathrm{S}_{2} \mathrm{Cl}_{2} /$ pyridine gave selectively 4,5,6-trichlorobenzo[6,7]cyclohepta[1,2-d][1,2,3]dithiazole 11 independent of the quantities of reagents; the best yield of $\mathbf{1 1}(61 \%)$ was obtained when 6 equiv of $\mathrm{S}_{2} \mathrm{Cl}_{2}$ and 8 equiv of pyridine were employed (Scheme 5).

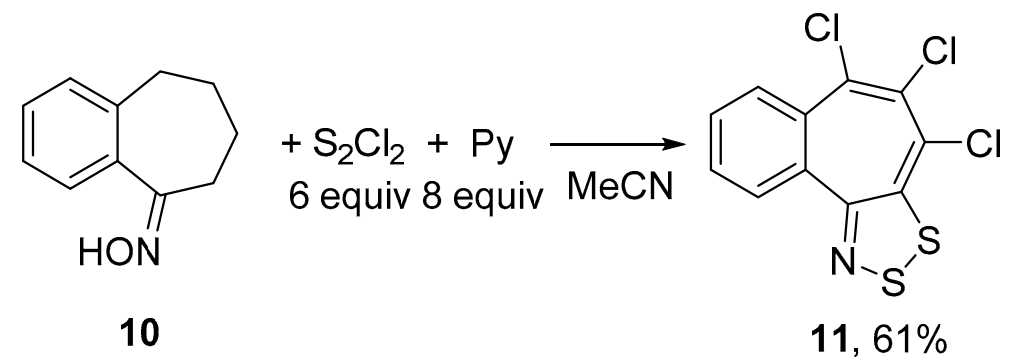

Scheme 5. Reaction of oxime 10 with $\mathrm{S}_{2} \mathrm{Cl}_{2}$ /pyridine to give dithiazole 11 .

1,4-Naphthoquinone oxime 12 treated with 3 equiv of $\mathrm{S}_{2} \mathrm{Cl}_{2}$ and 4 equiv of pyridine gave 4-chloro-5H-naphtho[1,2- $d][1,2,3]$ dithiazol-5-one $\mathbf{1 3}$ in 74\% yield (Scheme 6). The structure of $\mathbf{1 3}$ was confirmed by single-crystal XRD (Figure 1). 


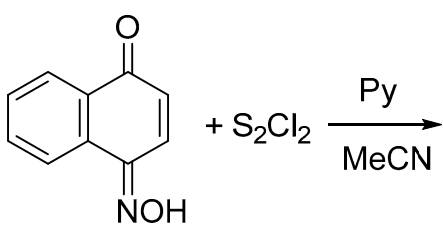

12<smiles>O=c1c(Cl)c2ssnc-2c2ccccc12</smiles>

$13,74 \%$

Scheme 6. Reaction of oxime 12 with $\mathrm{S}_{2} \mathrm{Cl}_{2}$ /pyridine to give dithiazole 13 .

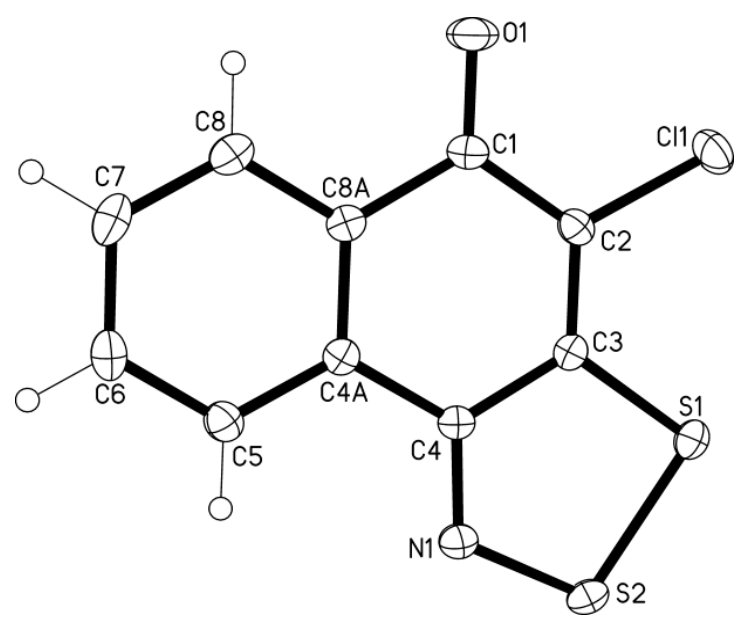

Figure 1. XRD molecular structure of dithiazole 13 (displacement ellipsoids at 50\%, atoms $\mathrm{H}$ are shown as cycles). Selected bond distances $(\AA)$ and angles $\left(^{\circ}\right)$ (crystallographic numbering): C3-S1 1.7264(5), S1-S2 2.0774(5), S2-N1 1.6297(13), N1-C4 1.3054(19), C4-C3 1.456(2), C1-O1 1.2301(19), C2-Cl1 1.7259(16); C3-S1-S2 92.18(5), S1-S2-N1 98.13(5), S2-N1-C4 117.09(11), N1-C4-C3 118.65(13), C4-C3-S1 113.94(10).

The molecule is perfectly planar and the bond distances and angles correspond to the statistical means [20]. The crystal packing reveals shortened contacts S...O together with $\pi-\pi$ and Cl- $\pi$ interactions [21].

An unexpected result was obtained with naphthoquinone oxime 14, an isomer of oxime 12. Treatment of 14 with $\mathrm{S}_{2} \mathrm{Cl}_{2}$ /pyridine in $\mathrm{MeCN}$ gave a mixture of two isomeric chloronaphthodithiazolones 13 and 15 in comparable yields (Scheme 7). First of all, it was shown that 14 was an individual compound with no traces of its isomer 12. Special experiments on individual 13 and 15 showed that 15 converts into 13 when treated with $\mathrm{S}_{2} \mathrm{Cl}_{2}$ /pyridine, whereas 13 remains unchanged. Effectively, the dithiazole ring moved from $\alpha$ - to $\beta$-position, with respect to the keto group, and the reaction under discussion represents a novel rearrangement. Earlier, similar processes were discovered by us for fused 1,2,3,4,5-pentathiepines [22-24]. Apparently, the mechanism of this rearrangement includes dithiazole ring-opening in $\mathbf{1 5}$ by the action of the chlorinating agent (i.e., $\mathrm{S}_{2} \mathrm{Cl}_{2}$ ) followed by the ring-closure to afford 13 (Scheme 7). The scope of this rearrangement is under consideration.

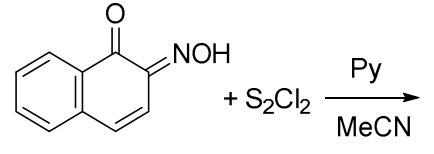

14<smiles></smiles>

$15,24 \%$
$13,21 \%$

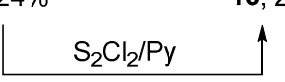

Scheme 7. Reaction of oxime 14 with $\mathrm{S}_{2} \mathrm{Cl}_{2}$ /pyridine to give dithiazoles $\mathbf{1 5}$ and 13. 


\subsection{Electrochemical Reduction and Oxidation of Dithiazole $\mathbf{1 3}$}

Recently, it was shown that benzo-fused 1,2,3-dithiazoles are able to form persistent radical-anions (RAs) under conditions of electrochemical and chemical reduction and one of the RAs was isolated in the form of thermally-stable paramagnetic salts [6,7]. Amongst compounds synthesized in this work napthoquinone-fused derivatives $\mathbf{1 3}$ and $\mathbf{1 5}$ are especially interesting in the context of RAs since one may expect some concentration of a negative charge on the $\mathrm{C}=\mathrm{O}$ moieties (ultimately leading to the $\mathrm{C}-\mathrm{O}^{-}$bonding situation) enlarging their ability to coordinate metal cations. This might be a new approach to the design and synthesis of sulfur-nitrogen $\pi$-heterocyclic RA salts as potential building blocks of magnetic functional materials [25-29].

The electrochemical behavior of $\mathbf{1 3}$ was studied and found to be a very complex multistep process. Thus, the CV of 13 in MeCN $(0>E>-2.0 \mathrm{~V})$ contains six irreversible peaks in the cathodic branch of the voltammogram. The additional quasi-reversible peaks $1 c^{\prime}-1 a^{\prime}$ and $2 c^{\prime}-2 a^{\prime}$ were observed in the second cycle at lower potentials than $E_{\mathrm{p}}^{1 \mathrm{C}}$ (Figure 2).

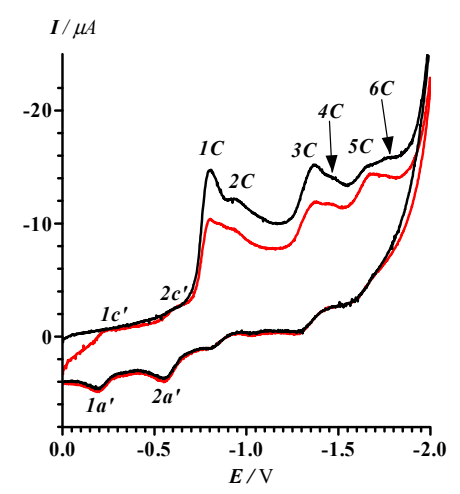

Figure 2. $\mathrm{CV}$ of $\mathbf{1 3}$ in $\mathrm{MeCN}$ (black curve: first cycle; red curve: second cycle). The potential sweep range was $0>E>-2.0 \mathrm{~V}$ and the potential sweep rate $100 \mathrm{mV} \cdot \mathrm{s}^{-1}$. Peak potentials $\left(-E_{\mathrm{p}}^{i j}\right.$ [30], $\left.\mathrm{V}\right)$ : $1 C, 0.80 ; 2 \mathrm{C}, 0.93 ; 3 \mathrm{C}, 1.37 ; 4 \mathrm{C}, 1.47 ; 5 \mathrm{C}, 1.68,6 \mathrm{C}, 1.76 ; 1 \mathrm{c}^{\prime}, 0.24 ; 1 \mathrm{a}^{\prime}, 0.19 ; 2 \mathrm{c}^{\prime}, 0.62 ; 2 \mathrm{a}^{\prime}, 0.56$.

With a limited potential sweep covering only reduction peaks $1 \mathrm{C}$ and $2 \mathrm{C}(0>E>-1.2 \mathrm{~V})$, peaks $1 c^{\prime}-1 a^{\prime}$ and $2 c^{\prime}-2 a^{\prime}$ did not vanish (Figure 3a). Moreover, further decrease in the potential sweep down to the range $0>E>-0.88 \mathrm{~V}$ embracing only the first irreversible step of the reduction of $\mathbf{1 3}$ (Figure $3 \mathrm{~b}$ ) did not cause any qualitative change in the compound's CV. We conclude that both electrode processes $1 c^{\prime}-1 a^{\prime}$ and $2 c^{\prime}-2 a^{\prime}$ belong to the product(s) of transformation of $\mathbf{1 3}$ at the first step of its reduction, and their currents are kinetically controlled by the reactions at the peak $1 \mathrm{C}$.

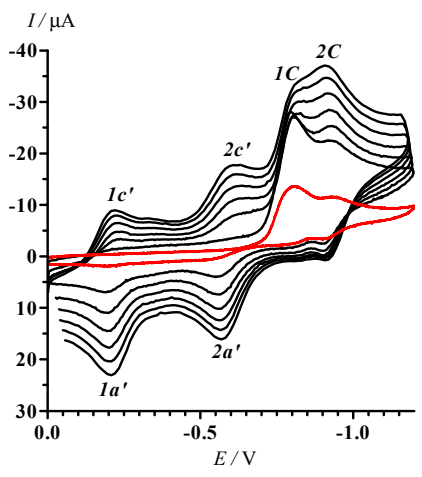

(a)

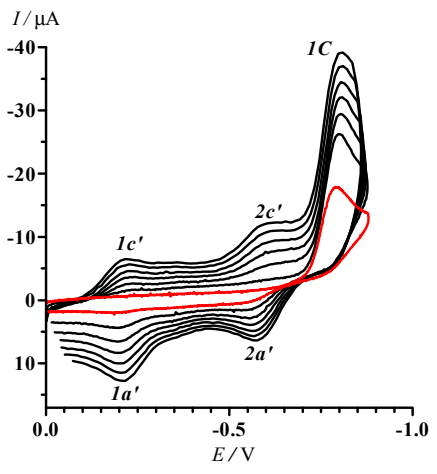

(b)

Figure 3. CVs of 13 in $\mathrm{MeCN}$ with potential sweep ranges $0>E>-1.2$ (a) and $0>E>-0.88$; (b) V. Potential sweep rates were 50 (first cycle, red curve), 250, 450, 650. 850, 1050, and 1250 (2-7 cycles, black curves) $\mathrm{mV} \cdot \mathrm{s}^{-1}$. 
The electrochemical reduction of $\mathbf{1 3}$ could be accompanied by its rapid irreversible dechlorination initiated by electron transfer ( $c f$. [31]). Additionally, the bond $\mathrm{C}=\mathrm{N}$ of the 1,2,3-dithiazole ring can undergo irreversible reduction in the RA state of a molecule, or the ring can be opened by the cleavage of S-S or/and S-N bonds ( $c f$. [32]). However, it is impossible to assign, unambiguously, these processes to the peaks $1 \mathrm{C}$ or $2 \mathrm{C}$. No long-lived paramagnetic products were observed by conventional EPR spectroscopy under stationary electrolysis of $\mathbf{1 3}$ in the range of potentials $-0.8>E>-1.8 \mathrm{~V}$.

$\mathrm{CV}$ of $\mathbf{1 3}$ in oxidative area of potentials is characterized by the only irreversible peak $1 \mathrm{~A}(\mathrm{Ox})$ at the potential $E_{\mathrm{p}}^{1 \mathrm{~A}(\mathrm{Ox})}=1.53 \mathrm{~V}$ (Figure 4). An additional irreversible peak $2 \mathrm{C}(\mathrm{Ox})\left(E_{\mathrm{p}}^{2 \mathrm{~A}(\mathrm{Ox})}=0.85 \mathrm{~V}\right)$ corresponding to the reduction of oxidation products of $\mathbf{1 3}$ is observed in the cathode branch of the $\mathrm{CV}$.

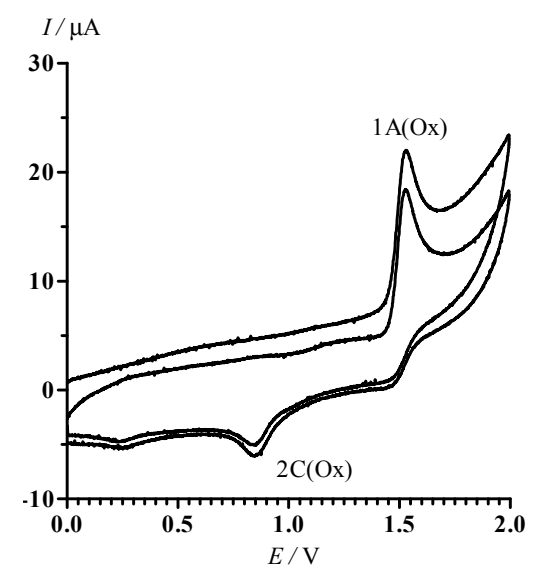

Figure 4. $\mathrm{CV}$ of 13 in $\mathrm{MeCN}$ in the range of potential sweep $0<E<2.0 \mathrm{~V}$. The potential sweep rate was $100 \mathrm{mV} \cdot \mathrm{s}^{-1}$.

Overall, the electrochemical behavior of $\mathbf{1 3}$ is characterized by a large number of multistage irreversible processes and their interpretation is a real challenge. Due to this complexity, at the current state of research only a qualitative description of the electrochemical behavior of $\mathbf{1 3}$ is possible. For further work preparative electrochemical reduction of $\mathbf{1 3}$ at controlled potentials is planned to obtain samples of reduction products enable their conventional characterization, together with generation of RAs from chlorine-less 1,2,3-dithiazoles such as 4 and related derivatives.

\section{Experimental Section}

\subsection{General Information}

Elemental analyses for C, H, and N were performed with Perkin Elmer 2400 Elemental Analyser (Perkin Elmer, Waltham, MA, USA). Melting points were determined on a Boetius hot-stage apparatus and are uncorrected.

${ }^{1} \mathrm{H}(300.1 \mathrm{MHz})$ and ${ }^{13} \mathrm{C}(75.5 \mathrm{MHz}) \mathrm{NMR}$ spectra were taken for $\mathrm{CDCl}_{3}$ solutions with a Bruker AM-300 (Bruker AXS Handheld Inc., Kennewick, WA, USA).

MS spectra (EI, $70 \mathrm{eV}$ ) were obtained with a Finnigan MAT INCOS 50 (Hazlet, NJ, USA), and high-resolution MS spectra with a Bruker micrOTOF II (Bruker Daltonik Gmbh, Bremen, Germany) instruments using electrospray ionization. The measurements were operated in a positive ion mode (interface capillary voltage $-4500 \mathrm{~V}$ ) or in a negative ion mode $(3200 \mathrm{~V})$; mass range was from $\mathrm{m} / z 50$ to m/z 3000 Da; external or internal calibration was done with Electrospray Calibrant Solution (Fluka). A syringe injection was used for solutions in $\mathrm{MeCN}$, methanol, or water (flow rate $3 \mu \mathrm{L} \cdot \mathrm{min}^{-1}$ ). Nitrogen was applied as a drying gas; interface temperature was $180^{\circ} \mathrm{C}$.

IR spectra were measured with a Specord M-80 instrument (Carl Zeiss, Jena, Germany) in KBr pellets.

Oximes 3 [33], 7 [34], 12 [35] and 14 [36] were prepared according to the published procedures. 


\subsection{General Procedure for the Reaction of Cyclic Oximes with $\mathrm{S}_{2} \mathrm{Cl}_{2}$ and Pyridine in Acetonitrile}

At $-25^{\circ} \mathrm{C}$ and under argon, $\mathrm{S}_{2} \mathrm{Cl}_{2}(0.24 \mathrm{~mL}, 3.0 \mathrm{mmol}$; or $0.48 \mathrm{~mL}, 6.0 \mathrm{mmol})$ was added dropwise to a stirred solution of oxime $(1.0 \mathrm{mmol})$ and pyridine $(0.32 \mathrm{~mL}, 4.0 \mathrm{mmol}$; or $0.64 \mathrm{~mL}, 8.0 \mathrm{mmol})$ in dry $\mathrm{MeCN}(10 \mathrm{~mL})$. The mixture was stirred for $0.5 \mathrm{~h}$ at $-5-0{ }^{\circ} \mathrm{C}$, for $24 \mathrm{~h}$ at ambient temperature, refluxed for $1 \mathrm{~h}$, filtered and the solvent was distilled off under reduced pressure. The residue was dissolved in $\mathrm{EtOH}(20 \mathrm{~mL})$, diluted by $\mathrm{H}_{2} \mathrm{O}(20 \mathrm{~mL})$ and extracted with ether $(3 \times 20 \mathrm{~mL})$. Combined extracts were washed with $\mathrm{H}_{2} \mathrm{O}(20 \mathrm{~mL})$, dried, and solvent was evaporated.

8-Chloroindeno[1,2-d]-1,2,3-dithiazole 2. Red solid, mp 108-110 ${ }^{\circ} \mathrm{C}\left(107-109^{\circ} \mathrm{C}\right.$ [12]). IR and MS spectra are similar to the literature data [12].

8-Phenylindeno[1,2-d]-1,2,3-dithiazole 4. Yellow solid, mp 111-112 ${ }^{\circ} \mathrm{C}\left(111-113{ }^{\circ} \mathrm{C}[12]\right) . \mathrm{IR}$ and MS spectra are similar to the literature data [12].

4,5,6-Trichlorocyclopenta[d][1,2,3]dithiazole 6a. Deep purple solid, mp 122-124 ${ }^{\circ} \mathrm{C}\left(125-127{ }^{\circ} \mathrm{C}[12]\right)$. IR and MS spectra are similar to the literature data [12].

Ethyl 5,6-dichlorocyclopenta[d][1,2,3]dithiazole-4-carboxylate 6 b. Yellow solid, mp 80-82 ${ }^{\circ} \mathrm{C}\left(83-84{ }^{\circ} \mathrm{C}[15]\right)$. IR and MS spectra are similar to the literature data [15].

5,7-Dichloro-6H-1,2,3-benzodithiazol-6-one 8. Red solid, mp 259-261 ${ }^{\circ} \mathrm{C}\left(257-258{ }^{\circ} \mathrm{C}\right.$ [13]). IR and MS spectra are similar to the literature data [13].

4,5,7-Trichloro-6H-1,2,3-benzodithiazol-6-one 9. Red solid, mp 214-215 ${ }^{\circ} \mathrm{C}\left(216-217^{\circ} \mathrm{C}\right.$ [13]). IR and MS spectra are similar to the literature data [13].

4,5,6-Trichlorobenzo[6,7]cyclohepta[1,2-d][1,2,3]dithiazole 11. Red solid, mp 119-121 ${ }^{\circ} \mathrm{C}\left(121-122{ }^{\circ} \mathrm{C}[12]\right)$. IR and MS spectra are similar to the literature data [12].

4-Chloro-5H-naphtho[1,2-d][1,2,3]dithiazol-5-one 13. Red solid, $\mathrm{mp} 230-233{ }^{\circ} \mathrm{C}\left(234-235{ }^{\circ} \mathrm{C}\right.$ [13]). IR and MS spectra are similar to the literature data [13].

9-Chloro-4H-naphtho[2,3-d][1,2,3]dithiazol-4-one 15. Blue solid, mp 192-195 ${ }^{\circ} \mathrm{C}$ (195-196 ${ }^{\circ} \mathrm{C}$ [13]). IR and MS spectra are similar to the literature data [13].

All compounds synthesized had correct elemental analyses and NMR spectra.

\subsection{Behavior of 1,2,3-Dithiazoles $\mathbf{1 3}$ and $\mathbf{1 5}$ in the $\mathrm{S}_{2} \mathrm{Cl}_{2} /$ Pyridine System}

At $-25^{\circ} \mathrm{C}$ and under argon, $\mathrm{S}_{2} \mathrm{Cl}_{2}(0.048 \mathrm{~mL}, 0.6 \mathrm{mmol})$ was added dropwise to a stirred solution of $15(25 \mathrm{mg}, 0.1 \mathrm{mmol})$ and pyridine $(0.064 \mathrm{~mL}, 8.0 \mathrm{mmol})$ in dry MeCN $(3 \mathrm{~mL})$. The mixture was refluxed for $2 \mathrm{~h}$, filtered and the solvent was distilled off under reduced pressure. The residue was dissolved in $\mathrm{CH}_{2} \mathrm{Cl}_{2}(7 \mathrm{~mL})$, washed with $\mathrm{H}_{2} \mathrm{O}(3 \times 2 \mathrm{~mL})$, dried over $\mathrm{MgSO}_{4}$, and the residue was separated by flash chromatography (silica gel Merck 60, hexane to hexane $/ \mathrm{CH}_{2} \mathrm{Cl}_{2}$ mixtures) to give 13 (10 mg, 39\%) and 15 (11 mg, 43\%).

In the experiment with 13 under the same reaction conditions it was quantitatively recovered.

\subsection{X-ray Diffraction}

XRD data of 13 were obtained with a Bruker Kappa Apex II CCD diffractometer (Bruker AXS Gmbh, Karlsruhe, Germany) using $\varphi$, $\omega$ scans of narrow $\left(0.5^{\circ}\right)$ frames with Mo K $\alpha$ radiation $(\lambda=0.71073 \AA)$ and a graphite monochromator. The structure of $\mathbf{1 3}$ was solved by direct methods and refined by full-matrix least-squares method against all $F^{2}$ in anisotropic approximation using the SHELX-97 (Bruker AXS, Madison, WI, USA) programs set [37]. The $\mathrm{H}$ atoms positions were calculated with the riding model. Absorption corrections were applied empirically using SADABS programs [38]. Shortened intermolecular contacts were analyzed using the PLATON [39] and MERCURY [40] programs. 
Compound 13 is orthorhombic, space group $P_{c a} 2_{1}, a=16.6153(6), b=3.8775(1), c=15.4168(6) \AA$, $V=993.24(6) \AA^{3}, Z=4, C_{10} \mathrm{H}_{4} \mathrm{ClNOS}_{2}, D_{\text {calc }}=1.697 \mathrm{~g} \cdot \mathrm{cm}^{-3}, \mu=0.770 \mathrm{~mm}^{-1}, \mathrm{~F}(000)=512$, crystal size $0.80 \times 0.20 \times 0.07 \mathrm{~mm}^{3}$, independent reflections $2254\left(R_{\text {int. }}=0.0404\right), \mathrm{wR}_{2}=0.0512, \mathrm{~S}=1.09$ for all reflections $(\mathrm{R}=0.0196$ for $2202 \mathrm{~F}>4 \sigma)$. Tables listing detailed crystallographic data, atomic positional parameters, and bond lengths and angles are available as CCDC 1468963 from the Cambridge Crystallographic Data Centre via www.ccdc.cam.ac.uk/data_request/cif.

\subsection{Cyclic Voltammetry}

The CV measurements on compound $13(\sim 1.2 \mathrm{mM}$ solutions in MeCN) were performed with a PG 310 USB potentiostat (HEKA Elektronik, Germany) at $293 \mathrm{~K}$ in an argon atmosphere at a stationary Pt spherical electrode $\left(\mathrm{S}=0.08 \mathrm{~cm}^{2}\right)$ with $0.1 \mathrm{M} \mathrm{Et}_{4} \mathrm{NClO}_{4}$ as a supporting electrolyte. A standard electrochemical cell (solution volume was $5 \mathrm{~mL}$ ) connected to the potentiostat with three-electrode scheme was used. Peak potentials were quoted with reference to a saturated calomel electrode (sce).

\section{Conclusions}

In this work, a new general procedure for the selective synthesis of carbocycle-fused 1,2,3-dithiazoles based on the reaction of cyclic oximes with $\mathrm{S}_{2} \mathrm{Cl}_{2}$ and pyridine in $\mathrm{MeCN}$ was established. With naphthalenone derivatives, a novel dithiazole rearrangement was discovered, i.e., isomerization of 15 into 13. The structure of 1,2,3-dithiazole 13 was confirmed by single-crystal XRD.

In most cases the hetero ring-closure was accompanied by chlorination. The presence of chlorine atoms in the 1,2,3-dithiazoles synthesized most likely causes instability of their reduced forms. Particularly, under the CV conditions and with compound 13, we speculate that hydrodechlorination occurs at a low potential. In any case, no long-lived paramagnetic products were observed by conventional EPR spectroscopy under stationary electrolysis of $\mathbf{1 3}$ in the potential range $-0.8>E>-1.8 \mathrm{~V}$. In further syntheses of carbocycle-fused 1,2,3-dithiazoles as potential precursors of persistent RAs ( $c f$. [6,7]) using the established procedure the chlorination must be prevented by appropriate substitution in starting oximes.

The effectiveness of the $\mathrm{S}_{2} \mathrm{Cl}_{2}$ /pyridine system in the chemistry described in this work motivates a special investigation of possible interaction/complexation between its components.

Acknowledgments: The authors are grateful to the Russian Science Foundation (grant no. 15-13-10022), the Leverhulme Trust (project IN-2012-094), and the Ministry of Education and Science of the Russian Federation (project of joint laboratories of Siberian Branch of the Russian Academy of Sciences and National Research Universities) for financial support of various aspects of this work.

Author Contributions: OAR and AVZ suggested research upon fused 1,2,3-dithiazoles towards their use in materials science; LSK and IVB performed synthetic work; LSK and OAR analyzed synthetic data; IYB obtained and analized XRD data; IGI and LAS obtained and analyse CV data; and OAR and AVZ wrote the paper. All authors read and approved the final manuscript.

Conflicts of Interest: The authors declare no conflict of interest.

\section{References and Notes}

1. Khmelnitsky, L.I.; Rakitin, O.A. 1,2-Oxa-3-azoles and 1,2-thia-3-azoles. In Comprehensive Heterocyclic Chemistry II; Storr, R.C., Ed.; Pergamon: Oxford, UK, 1996; pp. 433-452.

2. Rakitin, O.A. 1,2-Oxa/thia-3-azoles. In Comprehensive Heterocyclic Chemistry III; Katritzky, A.R., Ramsden, C.A., Scriven, E.F.V., Taylor, R.J.K., Eds.; Elsevier: Oxford, UK, 2008; pp. 1-36.

3. Konstantinova, L.S.; Rakitin, O.A. Synthesis and properties of 1,2,3-dithiazoles. Russ. Chem. Rev. 2008, 77, 521-546. [CrossRef]

4. Stable Radicals: Fundamentals and Applied Aspects of Odd-Electron Compounds; Hicks, R.G., Ed.; Wiley: Chichester, UK, 2010.

5. Rakitin, O.A. Stable heterocyclic radicals. Russ. Chem. Rev. 2011, 80, 647-659. [CrossRef] 
6. Makarov, A.Y.; Chulanova, E.A.; Semenov, N.A.; Pushkarevsky, N.A.; Lonchakov, A.V.; Bogomyakov, A.S.; Irtegova, I.G.; Vasilieva, N.V.; Lork, E.; Gritsan, N.P.; et al. A novel sulfur-nitrogen $\pi$-heterocyclic radical anion, (6H-1,2,3-benzothiadiazole-6-ylidene)malononitrilidyl, and its homo- and heterospin salts. Polyhedron 2014, 72, 43-49. [CrossRef]

7. Chulanova, E.A.; Irtegova, I.G.; Vasilieva, N.V.; Bagryanskaya, I.Y.; Gritsan, N.P.; Zibarev, A.V. Novel long-lived $\pi$-heterocyclic radical anion: A hybrid of 1,2,5-thiadiazo- and 1,2,3-dithiazolidyls. Mendeleev Commun. 2015, 25, 336-338. [CrossRef]

8. Appel, R.; Janssen, H.; Siray, M.; Knoch, F. Synthese und reaktionen des 4,5-dichlor-1,2,3-dithiazolium chlorids. Chem. Ber. 1985, 118, 1632-1643. [CrossRef]

9. Kim, K. Synthesis and reactions of 1,2,3-dithiazoles. Sulfur Rep. 1998, 21, 147-207. [CrossRef]

10. Oakley, R.T.; Reed, R.W.; Robertson, C.M.; Richardson, J.F. Naphthalene-1,2,3-dithiazolyl and its selenium-containing variants. Inorg. Chem. 2005, 44, 1837-1845. [CrossRef] [PubMed]

11. Neo, A.G; Carrillo, R.M.; Marcos, C.F. A straightforward synthesis of 2-aminobenzothiazoles from Herz compounds. Org. Biomol. Chem. 2011, 9, 4850-4855. [CrossRef] [PubMed]

12. Plater, M.J.; Rees, C.W.; Roe, D.G.; Torroba, T. Cyclopenta-1,2,3-dithiazoles and related compounds. J. Chem. Soc. Perkin Trans. 1 1993. [CrossRef]

13. Polo, C.; Ramos, V.; Torroba, T.; Rakitin, O.A.; Rees, C. W. One-pot synthesis of 1,2,3-benzodithiazol-6-ones. Tetrahedron 1998, 54, 223-232. [CrossRef]

14. Macho, S.; Rodriguez, T.; Torroba, T.; Rees, C.W. A novel oxime to pentathiepin cascade reaction. J. Chem. Soc. Chem. Commun. 2001. [CrossRef]

15. Macho, S.; Miguel, D.; Gomez, T.; Rodriguez, T.; Torroba, T. From cyclopentanone oximes to bis[1,2,3]dithiazolo-s-indacenes, cyclopenta[c][1,2]thiazine, pentathiepino-, tetrathiino-, and thienocyclopenta[1,2,3]dithiazoles as a rich source of new materials. J. Org. Chem. 2005, 70, 9314-9325. [CrossRef] [PubMed]

16. Rakitin, O.A.; Konstantinova, L.S. Sulfur monochloride in the synthesis of heterocyclic compounds. Adv. Heterocycl. Chem. 2008, 96, 175-229.

17. Rakitin, O.A. One-pot synthesis of sulfur heterocycles from simple organic substrates. Arkivoc 2009, 1, 129-149.

18. Rakitin, O.A.; Konstantinova, L.S. Design of sulfur heterocycles with sulfur monochloride: Retrosynthetic analysis and prospects. Mendeleev Commun. 2009, 19, 55-61.

19. Rakitin, O.A.; Konstantinova, L.S. Sulfur monochloride in organic synthesis. Russ. Chem. Rev. 2014, 83, 225-250.

20. Allen, F.H.; Kenard, O.; Watson, D.G.; Bramer, L.; Orpen, A.G.; Taylor, R. Tables of bond lengths determined by X-ray and neutron diffraction. Part 1. Bond lengths in organic compounds. J. Chem. Soc. Perkin Trans. II 1987. [CrossRef]

21. In the crystal of $\mathbf{1 3}$, the intermolecular contacts S...O are shortened to $2.84-2.91 \AA$ and form an infinite chains of molecules along the crystallographic axis $c$ (normal contact S. . O is 3.32 A. Rowland, R.S.; Taylor, R. Intermolecular nonbonded contact distances in organic crystal structures: Comparison with distances expected from van der Waals radii. J. Phys. Chem. 1996, 100, 7384-7391). These chains form infinite stacks along the axis $b$ through the arene-arene $\pi \cdots \pi$ interactions (centroid-to-centroid distance is $3.64 \AA$, interplanar separation $3.51 \AA$ ). Additionally to the $\pi \ldots \pi$ interactions, the $\mathrm{Cl} \cdots \pi$ interactions are observed, the atom-to-plane distance is $3.53 \AA$.

22. Konstantinova, L.S.; Rakitin, O.A.; Rees, C.W. One-pot synthesis of fused pentathiepins. Chem. Commun. 2002, 2009, 1204-1205.

23. Amelichev, S.A.; Konstantinova, L.S.; Lyssenko, K.A.; Rakitin, O.A.; Rees, C.W. Direct synthesis of fused 1,2,3,4,5-pentathiepins. Org. Biomol. Chem. 2005, 3, 3496-3501. [CrossRef] [PubMed]

24. Konstantinova, L.S.; Amelichev, S.A.; Rakitin, O.A. Regioselective synthesis of pentathiepins fused with pyrroles, thiophene and indoles. Russ. Chem. Bull. 2006, 55, 2081-2084. [CrossRef]

25. Lonchakov, A.V.; Rakitin, O.A.; Gritsan, N.P.; Zibarev, A.V. Breathing some new life into an old topic: Chalcogen-nitrogen $\pi$-heterocycles as electron acceptors. Molecules 2013, 18, 9850-9900. [CrossRef] [PubMed] 
26. Pushkarevsky, N.A.; Semenov, N.A.; Dmitriev, A.A.; Kuratieva, N.V.; Bogomyakov, A.S.; Irtegova, I.G.; Vasilieva, N.V.; Bode, B.E.; Gritsan, N.P.; Konstantinova, L.S.; et al. Synthesis and properties of the heterospin $\left(\mathrm{S}_{1}=\mathrm{S}_{2}=1 / 2\right)$ radical-ion salt bis(mesitylene)molibdenium(I) $[1,2,5]$ [thiadiazolo[3,4-c][1,2,5]thiadiazolidyl. Inorg. Chem. 2015, 54, 7007-7013. [CrossRef] [PubMed]

27. Semenov, N.A.; Pushkarevsky, N.A.; Suturina, E.A.; Chulanova, E.A.; Kuratieva, N.V.; Bogomyakov, A.S.; Irtegova, I.G.; Vasilieva, N.V.; Konstantinova, L.S.; Gritsan, N.P.; et al. Bis(toluene)chromium(I) $[1,2,5]$ thiadiazolo[3,4-c][1,2,5]thiadiazolidyl and $[1,2,5]$ thiadiazolo[3,4- $b]$ pyrazinidyl: New heterospin $\left(\mathrm{S}_{1}=\mathrm{S}_{2}=1 / 2\right)$ radical-ion salts. Inorg. Chem. 2013, 52, 6654-6663. [CrossRef] [PubMed]

28. Semenov, N.A.; Pushkarevsky, N.A; Lonchakov, A.V.; Bogomyakov, A.S.; Pritchina, E.A.; Suturina, E.A.; Gritsan, N.P.; Konchenko, S.N.; Mews, R.; Ovcharenko, V.I.; et al. Heterospin $\pi$-heterocyclic radical-anion salt: Synthesis, structure and magnetic properties of decamethylchromocenium [1,2,5]thiadiazolo[3,4-c][1,2,5]thiadiazolidyl. Inorg. Chem. 2010, 49, 7558-7564. [CrossRef] [PubMed]

29. Gritsan, N.P.; Zibarev, A.V. Chalcogen-nitrogen $\pi$-heterocyclic radical-anion salts: The synthesis and properties. Russ. Chem. Bull. 2011, 60, 2131-2140. [CrossRef]

30. In the potential $E_{\mathrm{p}}^{i j}$ designation, $\mathrm{i}$ is a number of peak, $\mathrm{j}=\mathrm{A}$ or $\mathrm{C}$ indicates the anode or cathode branch of the $\mathrm{CV}$ curve, respectively. An additional symbol $\mathrm{Ox}$ is related to $\mathrm{CV}$ in the area of oxidative potentials. The designation of corresponding currents is the same.

31. Vasilieva, N.V.; Irtegova, I.V.; Gritsan, N.P.; Lonchakov, A.V.; Makarov, A.Y.; Shundrin, L.A.; Zibarev, A.V. Redox properties and radical anions of fluorinated 2,1,3-benzothia(selena)diazoles and related compounds. J. Phys. Org. Chem. 2010, 23, 536-543. [CrossRef]

32. Konstantinova, L.S.; Knyazeva, E.A.; Obruchnikova, N.V.; Vasilieva, N.V.; Irtegova, I.G.; Nelyubina, Y.V.; Bagryanskaya, I.Y.; Shundrin, L.A.; Sosnovskaya, Z.Y.; Zibarev, A.V.; et al. 1,2,5-Thiadiazole 2-oxides, their benzo-fused derivatives and parent compounds: Selective synthesis, structural characterization and electrochemical properties. Tetrahedron 2014, 70, 5558-5568. [CrossRef]

33. Banzi, V.; Gila, L.; Santi, R.; Biagini, P.; Borsotti, G. Process for Preparing Elastomeric ep(d)m Copolymers. EP 0806436, 12 November 1997.

34. Kim, S.-H.; Kwon, J.-H.; Yoon, S.-H. An improved synthesis of 4'-hydroxydiclofenac. Bull. Korean Chem. Soc. 2010, 31, 3007-3009. [CrossRef]

35. Meyer, K.H.; Lenhardt, S. Die Reaktionsweise der Enole und der Phenole; ein Beitrag zur Kenntnis der ungesättigten Verbindungen. Liebigs Ann. Chem. 1913, 398, 66-82. [CrossRef]

36. Henriques, R.; Ilinski, M. Zur darstellung der nitrosonaphtole. Chem. Ber. 1885, 18, 704-706. [CrossRef]

37. Sheldrick, G.M. Crystal structure refinement with SHELXL. Acta Crystallogr. C 2015, 71, 3-8. [CrossRef] [PubMed]

38. SADABS. Version 2008-1; Bruker AXS: Madison, WI, USA, 2008.

39. Spek, A.L. PLATON, A Multipurpose Crystallographic Tool (Version 10M); Utrecht University: Utrecht, The Netherlands, 2003.

40. Macrae, C.F.; Edgington, P.R.; McCabe, P.; Pidcock, E.; Shields, G.P.; Taylor, R.; Towler, M.; van de Stree, J. Mercury: Visualization and analysis of crystal structures. J. Appl. Crystallogr. 2006, 39, 453-457. [CrossRef]

Sample Availability: Samples of all compounds are available from the authors.

(C) 2016 by the authors; licensee MDPI, Basel, Switzerland. This article is an open access article distributed under the terms and conditions of the Creative Commons Attribution (CC-BY) license (http://creativecommons.org/licenses/by/4.0/). 